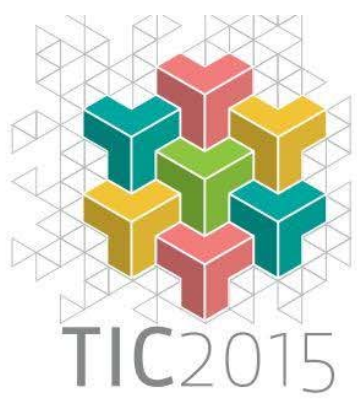

\title{
GESTÃO DO PROCESSO PROJETUAL ARQUITETÔNICO: CONCEITOS, METODOLOGIAS E FERRAMENTAS PARA VIABILIZAÇÃO DAS ETAPAS PROJETUAIS ${ }^{1}$
}

\author{
ARCHITECTURAL PROJECT PROCESS MANAGEMENT: CONCEPTS, \\ METHODOLOGY AND TOOLS TO ENABLE PROJECTS STEPS
}

\author{
Sandra Silva \\ Rainbow Produções e Eventos \\ sandrasilva.box@gmail.com \\ Patrícia Porto Carreiro \\ Universidade Federal de Pernambuco (UFPE) \\ ppc@ufpe.br
}

\begin{abstract}
Resumo
Este artigo apresenta um estudo que buscou o aprimoramento da qualidade do Processo Projetual Arquitetônico (PPA) através da utilização de recursos conceituais, metodológicos e ferramentais da área de Gestão de Projeto, integrados a outras plataformas de conhecimento da Administração e da Tecnologia da Informação e Comunicação. Objetivou-se a proposição de uma metodologia de integração destas plataformas para melhoria do PPA que além de descrever todas suas atividades e roteirizar suas etapas, apresenta uma forma de geri-las e integrá-las. Especificamente, utilizou-se o recurso de Plano de Gestão do Escopo para se propor a Metodologia de Integração de Plataformas de conhecimento - MIP na gestão do PPA, concretizada através da: [1] definição dos objetivos do escopo do PPA, [2] estruturação da proposta do PAA, [3] considerações para a gestão geral do PPA, [4] criação de briefings para as etapas do PPA, [5] estruturação do PPA através da Estrutura Analítica do Projeto (EAP) e, por fim, [6] apresentação das atividades e processos dentro da EAP agregando conceitos práticos e teóricos. Concluiu-se identificando-se vários softwares disponíveis como ferramentas de viabilização para execução dos roteiros indicados pela MIP e discutindo-se desdobramentos do estudo.
\end{abstract}

Palavras-chave: Processo Projetual Arquitetônico, Gestão de Projetos, TIC, Plataformas de Conhecimento.

\begin{abstract}
This article presents a study that looked for the quality improvement of Architectural Project Process (PPA) through the use of conceptual, methodologic and tools concepts in the Management of Project area, integrated to other knowledge platforms from Administration and from Information and Communication Technology. The aim is to propose a methodology that integrates these platforms in order to improve PPA that besides describing all its activities and to give a route to the stages, it presents a way to manage and integrate them. Specifically, it was used the resource from the Scope Plan of Management to propose the Knowledge Platform Integration Methodology - MIP in PPA management, materialized by [1] aims definition from the PPA scope, [2] organization from the PPA proposal, [3] PPA consideration and general management, [4] briefings creation to PPA stages, [5] PPA organization via Analytical Structure from the Project (EAP), and lastly, [6] presentation of activities and
\end{abstract}

\footnotetext{
${ }^{1}$ SILVA, S.; CARREIRO, P. P. Gestão do processo projetual arquitetônico: conceitos, metodologias e ferramentas para viabilização das etapas projetuais. In: ENCONTRO BRASILEIRO DE TECNOLOGIA DE INFORMAÇÃO E COMUNICAÇÃO NA CONSTRUÇÃO, 7., 2015, Recife. Anais... Porto Alegre: ANTAC, 2015.
} 


\section{TIC2015}

processes inside EAP adding theoretical and practical concepts. It was concluded that identifying many available software's as tools of feasibility to the execution of the MIP indicated routes and discussing some continuation to this study.

Key words: Architectural Project Process (PPA), Project Management, TIC, Knowledge Platform.

\section{INTRODUÇÃO}

O estudo apresentado neste artigo foi tema do trabalho de conclusão de graduação da principal autora deste, orientado pela aqui coautora, no Curso de Arquitetura e Urbanismo CAU da UFPE - Universidade Federal de Pernambuco, pautado na atuação profissional por mais de 15 anos da autora ${ }^{2}$. Tal amplitude de atuação, unido a uma inquietação e sagacidade de percepção, fez com que o trabalho final de curso fosse direcionado para uma tentativa de decodificação dos problemas encontrados neste cotidiano em busca da melhoria de qualidade do Processo Projetual Arquitetônico (PPA) e seus possíveis desdobramentos.

A motivação principal do estudo advinha de um cenário de insatisfação generalizado, onde todos os envolvidos no PPA relatavam problemas constantes de naturezas diversas, conforme sintetizado na Tabela 1 e diagnosticado através de questionários aplicados aos seus principais atores (Arquitetos, Clientes e Construtoras). Mas, tais problemas, a princípio, poderiam ser resolvidos ou minimizados através da integração de recursos de plataformas de conhecimentos $^{3}$ (de gestão e tecnologia) aplicadas ao PPA, o que se configurou na principal hipótese do estudo em questão.

Tabela 1 - Amostragem das problemáticas relatadas pelos principais atores do PPA

\begin{tabular}{|c|c|c|}
\hline Arquitetos & Clientes & Obras \\
\hline $\begin{array}{l}\text { _Oscilação do volume de trabalhos } \\
\text { em contrapartida dos gastos fixos } \\
\text { do escritório. } \\
\text { _Indecisão de alguns clientes, e } \\
\text { mesmo conflito de interesses na } \\
\text { família._Protelação ou ausência } \\
\text { de pagamentos por parte do } \\
\text { cliente. } \\
\text { _Falta das informações inerentes } \\
\text { às necessidades e desejos dos } \\
\text { clientes._Alterações de última } \\
\text { hora. } \\
\text { _Conflito entre os horários das } \\
\text { equipes da obra. }\end{array}$ & $\begin{array}{l}\text { _Atrasos na entrega dos projetos e } \\
\text { _Atrasos no término da obra. } \\
\text { _Correções na obra. } \\
\text { _Dificuldade na confecção e } \\
\text { construção de alguns elementos. } \\
\text { _Problemas não previstos na obra. } \\
\text { _Orçamento além do previsto. }\end{array}$ & $\begin{array}{l}\text { _Problemas com a mão-de-obra: } \\
\text { atrasos, confecção errada ou fora } \\
\text { da exigência solicitada. } \\
\text { _Exigências burocráticas dos } \\
\text { Órgãos responsáveis pela } \\
\text { legalização. } \\
\text { _Atrasos. }\end{array}$ \\
\hline
\end{tabular}

Fonte: Elaborado pelas autoras.

\footnotetext{
2 Autora com atuação junto a mais de 100 escritórios de arquitetura da cidade de Recife e suas respectivas obras, como assessora técnica, abrangendo o apoio ao desenvolvimento de projeto arquitetônico, detalhamento e acompanhamento de obra, onde também foram necessários conhecimentos administrativos, de gestão e de tecnologias de informação e comunicação.

3 Neste artigo a expressão plataforma de conhecimento é usado para expressar um conjunto delimitado de conhecimentos e processos.
} 


\section{TIC2015}

Diante deste contexto, começou-se uma jornada para identificar onde estaria a origem dos problemas e quais soluções seriam indicadas. Primeiro, foi necessário abordar o tema em um nível de abstração alto, deixando os detalhes para uma outra etapa do estudo, como orientado por uma das plataformas de conhecimento utilizada, na tentativa de encontrar o melhor momento ou fase para intervenção no PPA que pudesse resultar em melhoria efetiva do processo. No entanto, este nível de abstração foi responsável para que o tratamento proposto pelo estudo, ao longo de todo o processo, fosse uniforme e para que ações propostas pudessem ser facilmente entendidas em qualquer fase de aplicação.

Diante dos problemas relatados, foi necessário definir que ações poderiam resultar na melhoria das atividades a eles relacionadas. Melhado (2001) chama estes problemas de contradições entre competência de expressão formal ${ }^{4}$ e competência técnica ${ }^{5}$ e defende a compreensão e aplicação da Gestão de Projeto como meio de minimizar a ocorrência destes conflitos e maximizar a qualidade dos projetos executados. Pois, para minimizar os problemas identificados seria inócuo se responsabilizar a prática profissional/projetual, a falta de construtabilidade, o negligenciamento gerencional ou a falta de inventividade ${ }^{6}$. Era preciso entender suas partes e como elas se relacionam, o que foi descrito a seguir.

Assim, foi proposta uma metodologia que abordasse todas as etapas e atividades do PPA, mas entendendo que eram necessários conhecimentos complementares, ou seja, que essa metodologia atuaria numa plataforma onde outras áreas de conhecimentos seriam integradas para obtenção na melhoria de qualidade do processo projetual arquitetônico. Chamada nesse estudo de MIP. Cujo detalhamento será apresentado através da: [1] definição dos objetivos do escopo do PPA, [2] estruturação da proposta do PAA, [3] considerações para a gestão geral do PPA, [4] criação de briefings para as etapas do PPA, [5] organização estruturação do PPA através da Estrutura Analítica do Projeto (EAP) e, por fim, [6] apresentação das atividades e processos dentro da EAP agregando conceitos práticos e teóricos.

\section{PROCESSO PROJETUAL ARQUITETÔNICO}

$\mathrm{Na}$ abordagem para o melhor entendimento do PPA, decidiu-se dividir o processo em três fases conceituais coligadas e consecutivas: [1] Projeto Intenção, que contempla o processo de criação, onde o arquiteto utiliza métodos compositivos para alcançar a solução mais adequada; [2] Projeto Expressão, quando de posse de um vocabulário específico, utilizandose de representações gráficas e volumétricas, transforma as experiências anteriores, ainda que num estágio puramente mental, em representações bi e/ou tridimensionais, estando compreendido desde os primeiros esboços até o detalhamento técnico da obra a ser construída. Neste momento, destaca-se o uso de recursos das TIC, através da discriminação de softwares necessários para construção dessas representações gráficas. E por último, [3] Projeto Concretização, que prioriza a construção da obra e prática profissional in loco, como resposta efetiva de todo o planejamento e da integração das fases anteriores. De forma que, integradas, estas três fases se responsabilizariam pelo sucesso da materialização da ideia da solução espacial em obra construída.

\footnotetext{
${ }^{4}$ Expressão formal - toda ação no momento da criação, definição do partido e elaboração do projeto.

${ }^{5}$ Expressão Técnica - domínio de técnicas construtivas.

${ }^{6}$ Neste trabalho, o termo inventividade é empregado como a capacidade de criação de novas soluções para o projeto.
} 

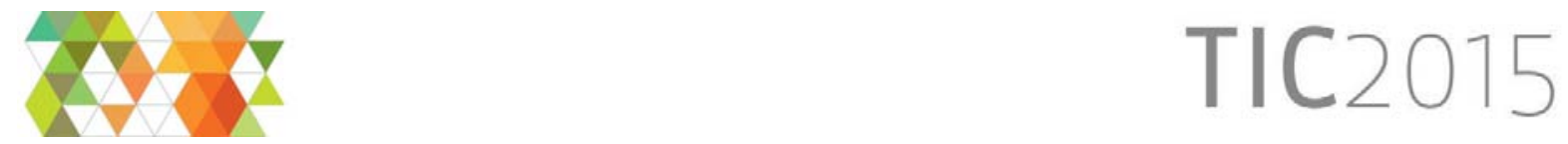

A definição Aedificatio de Vitruvio, na qual a boa arquitetura baseia-se em três conceitos: Firmitas, Utilitas e Venustas, comumente entendidos como solidez, funcionalidade e beleza, orienta a intenção do arquiteto até os tempos atuais.

[...] pode-se definir arquitetura como construção concebida com a intenção de ordenar e organizar plasticamente o espaço, em função de uma determinada época, de um determinado meio, de uma determinada técnica e de um determinado programa (COSTA, 2004, p. 246 Apud SILVA, 2009, p. 28).

Na tentativa de encontrar um roteiro harmônico, preciso e efetivo fez com que cada fase do PPA fosse entendida, a princípio, de forma conceitual e subdividida. Inspirou-se no preceito analítico de René Descartes descrito na sua obra o Discurso do Método, onde apresenta que qualquer problema poderia ser solucionado dividindo-o em parte menores de menor complexidade, e através de uma maior definição, chegaria se a um entendimento do todo.

\subsection{Projeto Intenção}

Silva (2009) definiu esta fase do PPA como:

Esta intenção existiu, sem origens definidas, com uma lógica própria, individualizada, compartilhada muitas vezes. Contudo existiu e atuou por uma causa maior, a expressão dos anseios arquitetônicos, do desejo de uma obra concretizada - a expressão de uma ideia que se vê construída. Neste momento todos seriam gênios da sua própria criatividade, com o domínio do pensamento e habilidade para expressá-lo e representá-lo, e mais, materializá-lo. Rotineiramente, isso ocorre nos recintos acadêmicos e na prática profissional (p. 31).

Para análise da primeira fase, tentou-se identificar e sintetizar métodos de composição adotados para definição e início do projeto arquitetônico, conforme relacionado na Tabela 2. Nesta análise, observou-se que as dificuldades encontradas neste momento do PPA, na grande maioria, ainda se manifestavam na Academia quando do êxito na indicação de um método ou modelo para guiar o aprendizado do aluno de Arquitetura. $O$ fato é que o aluno precisa de referências teóricas e práticas para desenvolver suas próprias ideias de maneira reflexiva e para desenvolver seu próprio método compositivo, o que pode ser facilitado pelo estudo de outros métodos.

Atualmente esta fase já vem sendo permeada de ferramentas auxiliares de concepção, como no caso do mapa mental. Segundo Porto Carreiro e Rêgo (2014) a realização da experiência pedagógica junto aos alunos com o uso do mapa mental nesta fase inicial atingiu os objetivos de provocar no estudante a reflexão do processo projetual e da importância da gestão de informação. O exercício em questão utilizou softwares e aplicativos para inserir os mais diversos dados - como fotos, vídeos, mapas, links - na construção do mapa mental de cada projeto. 


\section{敢}

\section{TIC2015}

Tabela 2 - Métodos compositivos

\begin{tabular}{|c|c|}
\hline Método & Características \\
\hline Beaux Arts & $\begin{array}{l}\text { O processo evolui do todo para as partes; Desenvolvimento de um partido } \\
\text { (concepção básica de um edifício);Esquema inicial em diagrama, estrutura } \\
\text { sob a qual irá regulamentar o projeto. }\end{array}$ \\
\hline $\begin{array}{l}\text { Composição contemporânea } \\
\text { (Segundo Mahfuz) }\end{array}$ & $\begin{array}{l}\text { Informação preliminar é interpretada e organizada de acordo com as } \\
\text { prioridades. Projeto a partir de imagens conceituais, tornando possível a } \\
\text { passagem do pensamento pragmático para o criativo, do espaço métrico dos } \\
\text { números para um espaço visionário de sistemas coerentes. Baseado em } \\
\text { valores qualitativos. Resultado de uma síntese analítica dos aspectos mais } \\
\text { importantes do problema arquitetônico. }\end{array}$ \\
\hline Teoria de Laugier & $\begin{array}{l}\text { O processo visa a união das partes, onde cada parte deve ter função } \\
\text { justificada pela razão sem se ater ao modo de sua união. A arquitetura } \\
\text { deveria imitar a "natureza materializada", e não a renascentista ou barroca. }\end{array}$ \\
\hline Teoria de Nagel & $\begin{array}{l}\text { O processo como todo possui uma extensão espacial e que assim se } \\
\text { manifesta e se compõe. }\end{array}$ \\
\hline Teoria de Alberti & O processo se dá pela definição de partes principais e partes secundárias. \\
\hline Teoria da totalidade & $\begin{array}{l}\text { Totalidade construtiva ou analítica: construção por partes, organização por } \\
\text { princípios. Totalidade visual: percebido entre a fácil identificação no contexto } \\
\text { na relação figura-fundo. Totalidade associativa: associa outros conceitos para } \\
\text { sua complementariedade, tais como a beleza e a ordem. }\end{array}$ \\
\hline Método Inovativo (Mahfuz) & $\begin{array}{l}\text { Resolução de problemas sem precedentes ou com uma solução } \\
\text { diferenciada.O detalhes faz a diferença. Através de analogias visuais, } \\
\text { estruturais ou filosóficas. }\end{array}$ \\
\hline Método Tipológico (Mahfuz) & $\begin{array}{l}\text { Definição de um tipo, estrutura regrada que classifica e serve como modelo } \\
\text { para outros casos. }\end{array}$ \\
\hline Método Mimético (Mahfuz) & Imitação de alguma referência de modelo já existente. \\
\hline Método Normativo (Mahfuz) & Criação através de regras e princípios reguladores. \\
\hline $\begin{array}{l}\text { Modelo Intuitivo/ Caixa Preta } \\
\text { (Salama e Del Rio) }\end{array}$ & O processo do projeto seria um mistério, sem controle ou lógica. \\
\hline Caixa de Vidro (Salama) & $\begin{array}{l}\text { Processo racional, mesmo que o arquiteto não tenha explicação sobre o } \\
\text { processo, há uma definição dos objetivos, critérios, variáveis. }\end{array}$ \\
\hline $\begin{array}{l}\text { Projeto Comunitário } \quad \text { (Sanoff } \\
\text { através de Salama) }\end{array}$ & Desenho participativo. \\
\hline
\end{tabular}

Fonte: Elaborado pelas autoras com base na bibliografia adotada: Boudon (2002), Carsalade (2003).

\subsection{Projeto Expressão}

Ainda sobre o uso de modelos teóricos para apoio a condução do PPA, Boudon (2002) orienta:

Historicamente, aparecem novos modelos de conhecimento organizado dos procedimentos de concepção da arquitetura, resultantes de múltiplos cortes do processo de concepção e do projeto. A visão do racionalismo, por exemplo, vê as possibilidades de um controle racional da atividade artística, descrevendo as etapas e momentos da concepção arquitetural, as modalidades de produção ou composição das formas arquiteturais na representação figurativa. A sua finalidade teórica acompanha-se de uma finalidade de eficiência profissional - ou pedagógica (p.70).

Esta fase compreende a transformação das ideias projetuais em representações bi e tridimensionais. Contudo, neste artigo, entende-se as representações gráficas não sendo apenas para comunicar a terceiros as ideias projetuais, mas fazendo parte da própria construção delas. O PPA visto como um experimento global reflexivo concretizado pelas 
representações gráficas foi defendido por Schön (2000) que o descreveu pelo envolvimento do aluno e o problema projetual, sendo desenvolvido em três dimensões: [1] domínios da linguagem, [2] implicações de suas descobertas e [3] mudanças de postura.

A concepção do arquiteto, que se dá no plano das imagens mentais, não se transforma diretamente na obra, que se verifica no plano do mundo concreto. Entre concepção e obra interpõe-se a etapa projetual, cuja finalidade é fixar, através de um conjunto de símbolos, os traços da concepção, isto é, das imagens mentais (SILVA, 1985, p. 112, nosso grifo).

As representações gráficas são auxiliadas por softwares que utilizam diferentes plataformas computacionais, como CAD (Computer Aided Design - Projeto Auxiliado pelo Computador), BIM (Building Information Modeling - Modelagem de Informação da Construção) ou GIS (Geographic Information System - Sistema de Informações Geográficas), através deles é possível aumentar a produtividade dos projetos, criando matrizes gráficas que possam ser replicadas e compartilhadas facilmente. No entanto, conhecimentos prévios são necessários para que o projetista domine não só as ferramentas de cada software, mas consiga entender e eleger o que e como será representado. Esse domínio e liberdade possibilitam a criação e alteração das demandas existentes, uma vez que essas necessidades acabam definindo como e quando cada software será atualizado para atender ao mercado. Ou seja, há necessidade de uma metodologia que oriente o projetista na tomada de decisão e escolhas que precisa fazer nesta etapa também.

\subsection{Projeto Concretização}

No estudo ora apresentado, foi importante que as etapas necessárias para concretização do projeto tivessem a maior amplitude possível, para que assim pudessem contemplar as diversas rotinas existentes nos escritórios de arquitetura. Para garantia da qualidade e padronização do conteúdo a ASBEA (Associação Brasileira dos Escritórios de Arquitetura) elaborou manuais técnicos para orientação dos profissionais: [1] Manual de Escopo de Serviços para Coordenação de Projetos e [2] Manual de Escopo de Projetos e Serviços de Arquitetura e Urbanismo balizaram este trabalho na roteirização das fases, etapas e atividades do PPA.

\section{MIP - Metodologia de Integração de Plataformas de Conhecimento no PPA}

A Metodologia proposta integra plataformas de conhecimentos distintas. Elegeu-se o gerenciamento do escopo no PPA para estruturar a análise inicial, roteirizando passo a passo as etapas necessárias para entender o processo e atuar nele.

O primeiro passo foi aplicar o gerenciamento do escopo para roteirização da MIP no PPA, conforme Tabela 3, traçamos o Plano de Gestão do Escopo específico para o PPA, onde foram organizadas as tarefas necessárias para atingir o objetivo principal, que era proporcionar a melhoria de qualidade no PPA. Nesta tabela foi indicado as atividades a serem executadas e consecutivamente o produto resultante com a conclusão de cada atividade. Estabeleceu-se então que seria necessário as definições dos próprios escopos e dos objetivos, criação de Briefing do conjunto de atividades de cada etapa, criação da Estrutura Analítica do Projeto (EAP). Essas diretrizes orientam as ações iniciais. 


\section{TIC2015}

Tabela 3 - Processo do gerenciamento do escopo no PPA

\begin{tabular}{|c|c|c|c|c|}
\hline \multicolumn{5}{|c|}{ A-1 Escopo adaptado } \\
\hline $\begin{array}{l}\text { A-1.1 Definição } \\
\text { dos objetivos }\end{array}$ & $\begin{array}{l}\text { A-1.2 Definição } \\
\text { do escopo }\end{array}$ & $\begin{array}{l}\text { A-1.3 Criação: } \\
\text { Briefing e EAP }\end{array}$ & $\begin{array}{c}\text { A-1.4 Relatar } \\
\text { processos do } \\
\text { EAP }\end{array}$ & $\begin{array}{c}\text { A-1.5 } \\
\text { Expectativas de } \\
\text { contribuição }\end{array}$ \\
\hline \multicolumn{5}{|c|}{ Atividades } \\
\hline $\begin{array}{l}\text { Definir objetivos na } \\
\text { realização do Plano } \\
\text { de escopo e delimitar } \\
\text { sua abrangência. }\end{array}$ & $\begin{array}{l}\text { Definir estrutura do } \\
\text { escopo. }\end{array}$ & $\begin{array}{l}\text { Criar briefing para as } \\
\text { atividades } \\
\text { componentes para o } \\
\text { processo projetual } \\
\text { arquitetônico. } \\
\text { Criar EAP para as } \\
\text { atividades } \\
\text { componentes para o } \\
\text { processo projetual } \\
\text { arquitetônico. }\end{array}$ & $\begin{array}{l}\text { Relatar os processos } \\
\text { adequados, a } \\
\text { estratégias e } \\
\text { ferramentas. }\end{array}$ & $\begin{array}{l}\text { Relatar expectativas } \\
\text { quanto ao escopo. }\end{array}$ \\
\hline \multicolumn{5}{|c|}{ Produto resultante } \\
\hline $\begin{array}{l}\text { - Descrição dos } \\
\text { objetivos e aplicação }\end{array}$ & - Escopo & $\begin{array}{l}\text { - Briefing de cliente } \\
\text { - Briefing do projeto } \\
\text { - Briefing da equipe } \\
\text { - Briefing do } \\
\text { acompanhamento de } \\
\text { obra } \\
\text { - Briefing pós-obra } \\
\text { - EAP do PPA }\end{array}$ & $\begin{array}{l}\text { - } \quad \text { Relatório de } \\
\text { processos }\end{array}$ & $\begin{array}{l}\text { - Relatório de } \\
\text { expectativas }\end{array}$ \\
\hline
\end{tabular}

Fonte: Elaborado pelas Autoras.

O Briefing do PPA, ver Tabela 4, roteiriza as informações necessárias para definição do PPA em geral, mas essa mesma estrutura pode ser construída em outras atividades ou etapas. Neste exemplo, engloba as atividades do Estudo Preliminar e acompanhamento das atividades iniciais, incluindo as atividades de manutenção e o que é necessário para checagem final dessas atividades. A mesma estrutura pode ser usada em qualquer outra atividade.

Tabela 4 - Briefing do Estudo Preliminar do PPA

\section{Inicial}

- Levantamento de dados fornecidos pelo cliente;

- Levantamento de dados através de pesquisas;

- Levantamento dos possíveis

fornecedores;

- Levantamentos das restrições legais;

- Elaboração de um cronograma para o

\section{Manutenção}

- Acompanhamento do projeto; - Sequência das etapas projetuais de acordo com a necessidade do projeto: levantamento de dados, criação do programa de necessidades, estudo preliminar, anteprojeto, projeto legal, projeto básico, projeto executivo, detalhamentos, acompanhamento da

\section{Checagem final}

- Check list de documentação necessária;

- Check list de documentação entregue;

- Relatório de atividades executadas. 


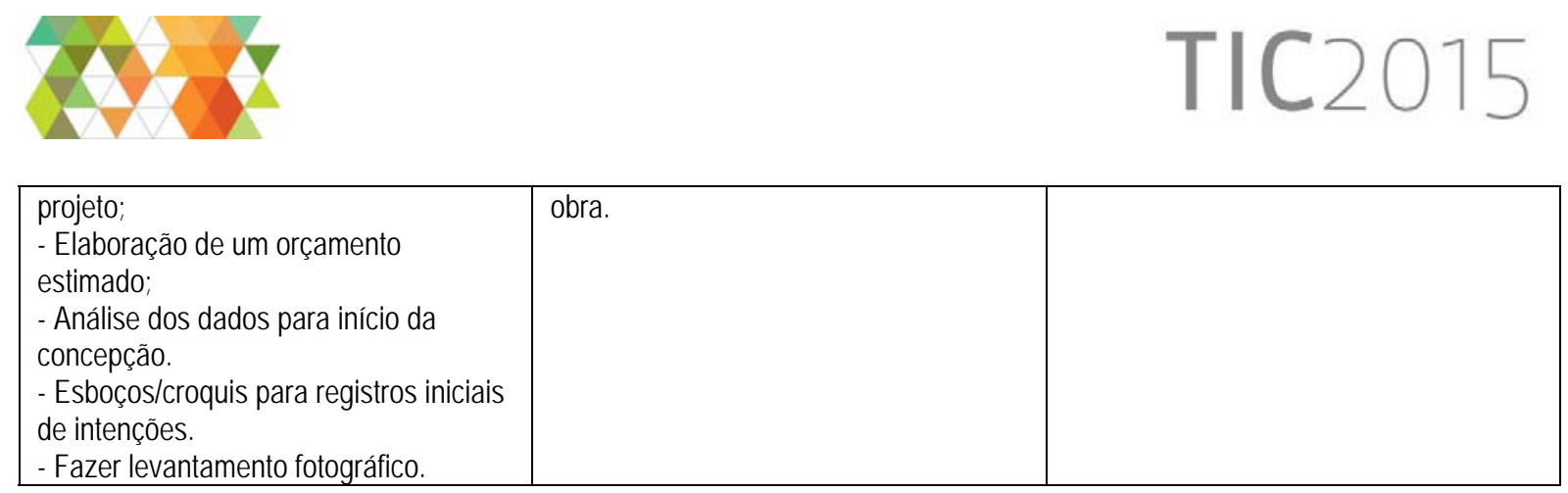

Fonte: Elaborado pelas Autoras.

Aprofunda-se a aplicação da MIP no PPA por construir a Estrutura Analítica do PPA - Geral, conforme Figura 1, estrutura em formato de árvore que hierarquiza as tarefas indicando as fases temporais de realização de cada etapa, sendo essas antes, durante e depois correlacionadas com as atividades conceituais de intenção, expressão e concretização. Com este método é possível compreender os quatro níveis do PPA: [1] etapas conceituais, [2] etapas temporais, [3] etapas da gestão do processo e [4] atividades do PPA. Possibilita a visualização das atividades e como elas se relacionam, quais as ações de entrada e saída, qual a hierarquia ou ordem dessas atividades.

Figura 1 - Estrutura analítica do PPA - Geral

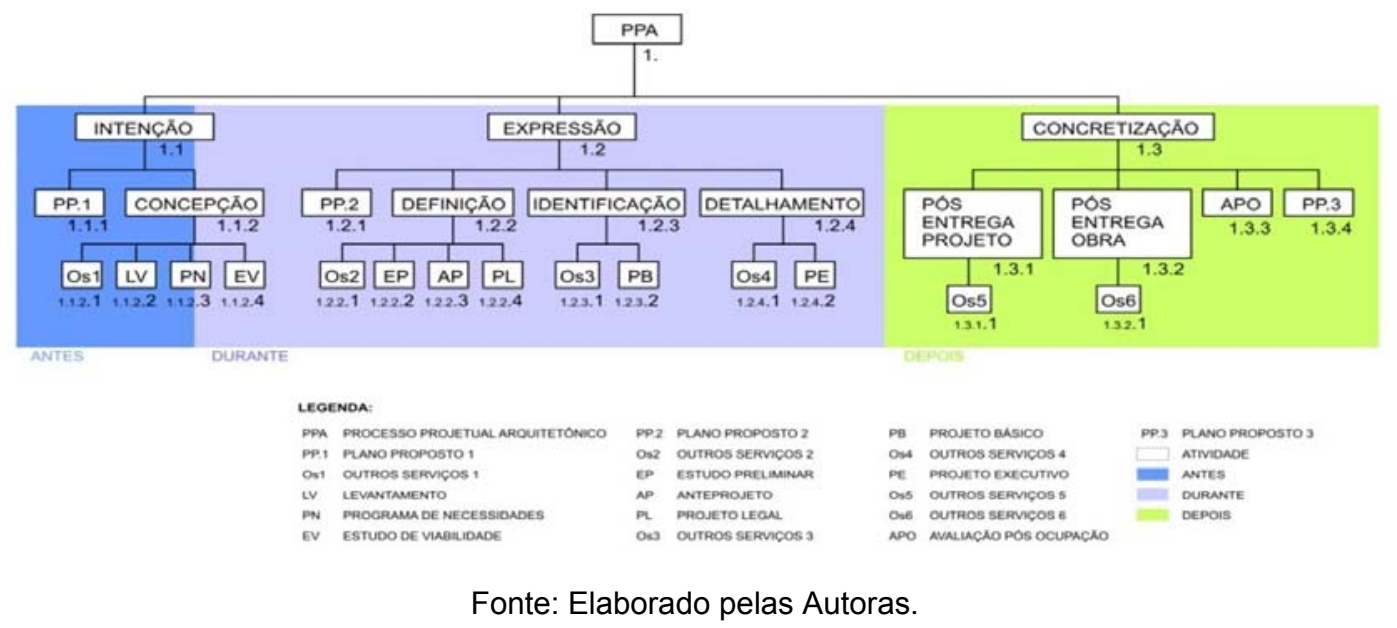

Bem como, na sequência vemos o Diagrama PERT (Program Evaluation and Review Technique - Avaliação de Programas e Revisão Técnica) do PPA, conforme Figura 2, onde é possível visualizar a coordenação das atividades. Esta ação dentro da MIP facilitou a compreensão e o acompanhamento das etapas e atividades, viu-se os caminhos de possibilidades e quão complexas são as relações entre as atividades do PPA, ainda considerando os níveis do PPA. 
Figura 2 - Diagrama PERT do PPA (segundo EAP)

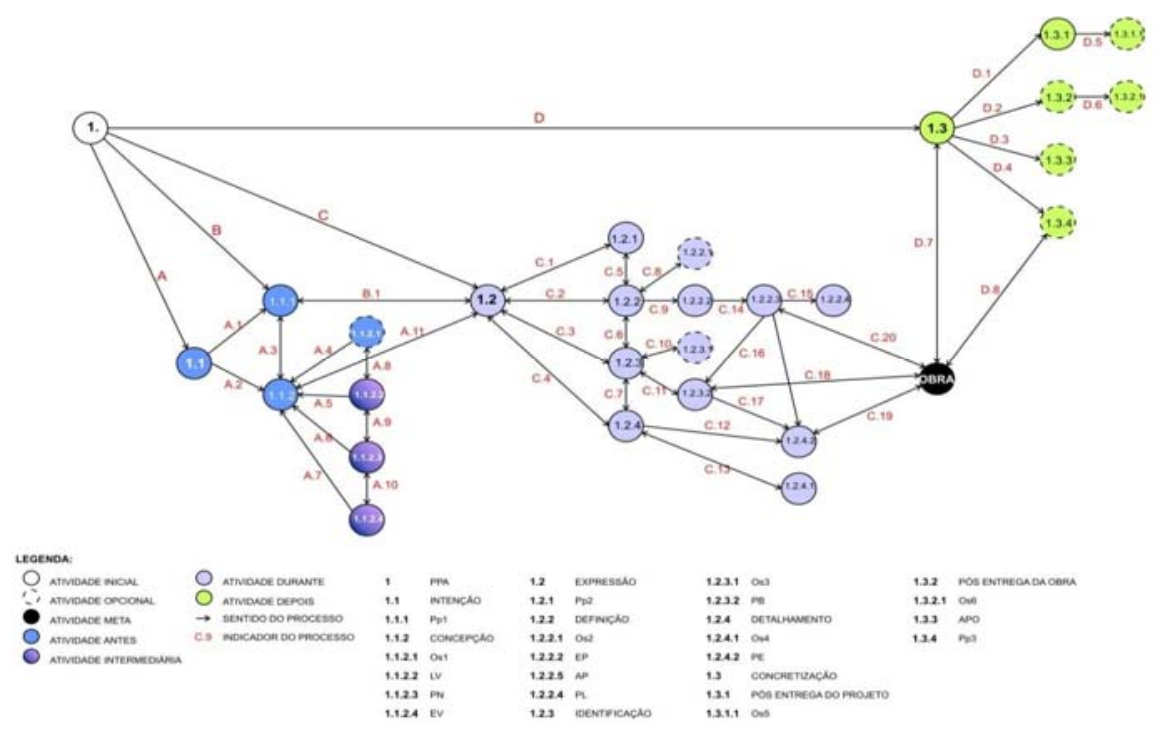

Fonte: Elaborado pelas Autoras.

E com a construção de um diagrama circular que permite a visualização das fases, etapas, tempo e duração relativa de cada atividade com o Ciclo Composto do PPA, conforme Figura 3.

Figura 3 - Sequência do Ciclo Composto

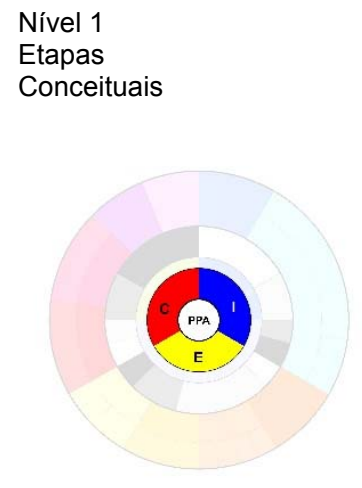

Nível 2
Etapas
Temporais
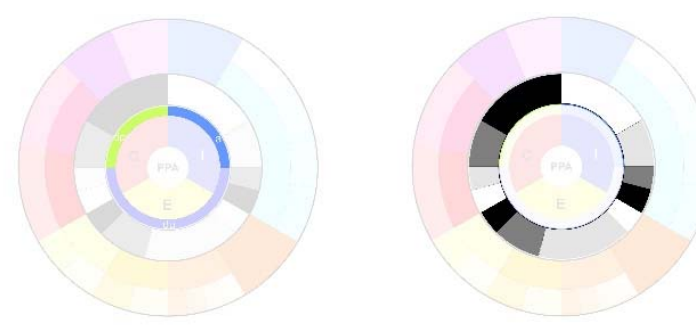

Nível 4

Atividades do

PPA

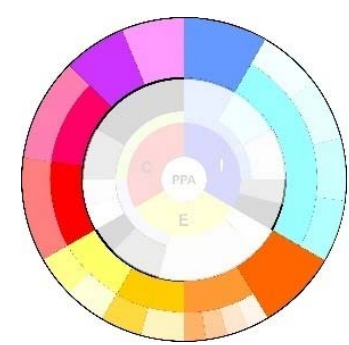

Fonte: Elaborado pelas Autoras.

A construção do Ciclo Composto do PPA talvez tenha sido a construção de maior sintetização do PPA, este diagrama permitiu a exposição de todas as atividades, assim como o acompanhamento e a evolução de cada atividade, é possível identificar com que etapa cada atividade está relacionada, nos níveis anteriores. Nos níveis conceituais se a atividade era Intenção, Expressão ou Concretização. Enquanto duração da obra, avaliando os níveis quanto ao tempo nas etapas temporais se esta aconteceria da fase inicial (antes), fase intermediária (durante) ou fase final (depois). Já no nível da Gestão do PPA, se a atividade estaria no processo como planejamento, organização, direção ou controle da atividade. Com esta metodologia era possível acompanhar cada atividade do PPA e saber o 

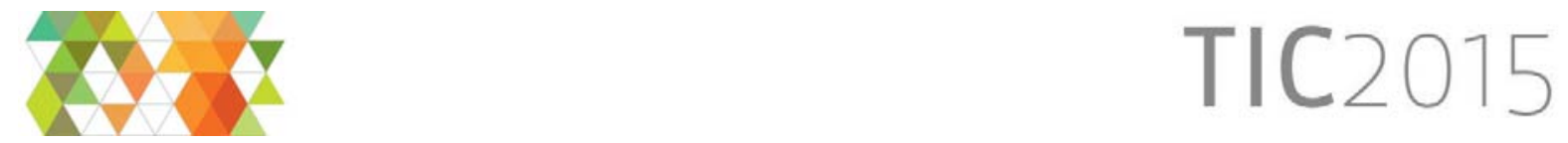

andamento dos projetos, como também estimar os recursos necessários para conclusão da atividade. Conforme Figura 4.

Figura 4 - Ciclo composto do PPA
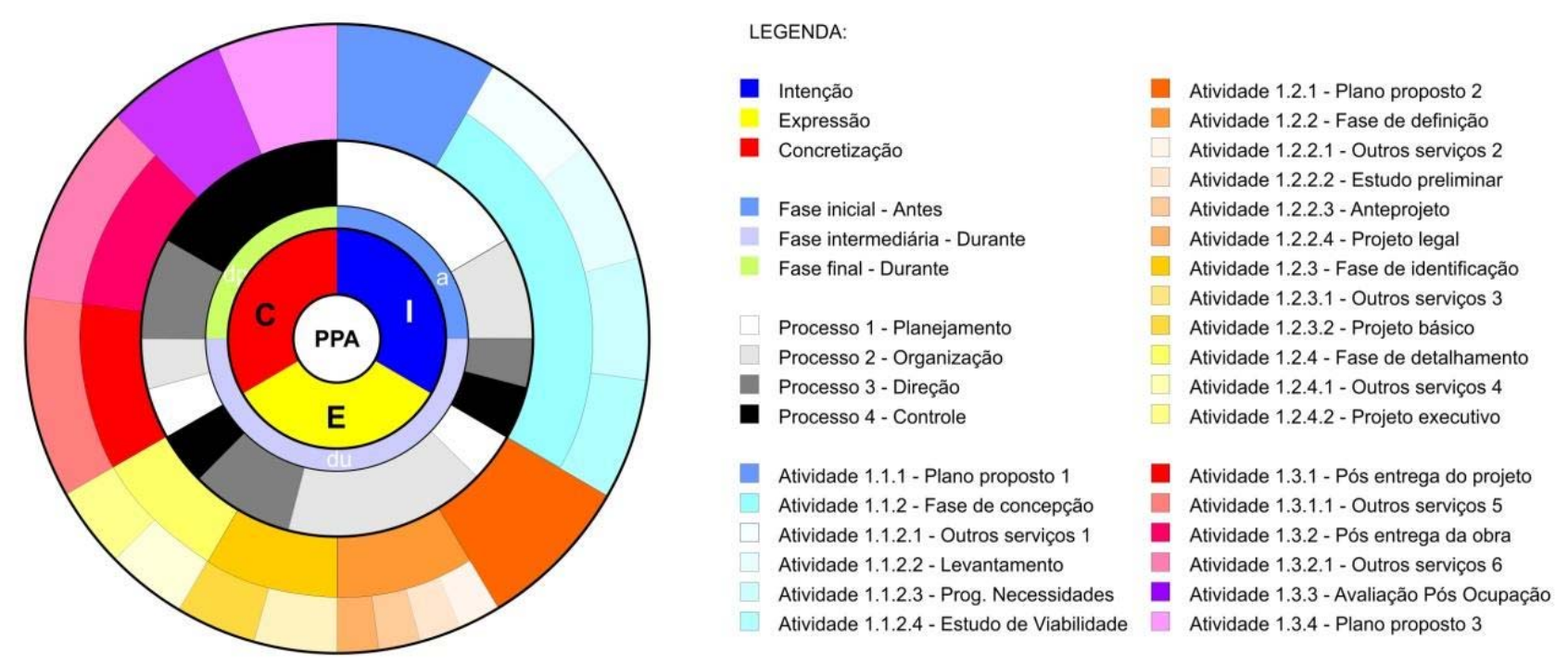

Fonte: Elaborado pelas Autoras.

\section{CONSIDERAÇÕES FINAIS}

O artigo apresentou um estudo que propõem uma melhoria no PPA através da aplicação da Metodologia de Integração de Plataformas de conhecimentos - MIP. Defendeu-se a aplicação da MIP como uma primeira abordagem na apreensão e organização do PPA. Propôs-se ainda, como desdobramento do estudo em trabalhos futuros, averiguar como a MIP pode ser viabilizada e aprimorada por meio do uso de ferramentas e processos das TIC. Ou seja, encontrar e estabelecer um plano de ação nas várias fases ou processos, ou estabelecendo a comunicação entre elas, seja essas soluções facilitadas através de qualquer sistema de informação (CAD, BIM, GIS).

Para validação deste estudo, seria necessário testar a MIP em casos reais do PPA, partes e todo do processo, de forma a se estabelecer as vantagens e desvantagens de sua aplicação, o que está sendo pensado como projeto de mestrado da principal autora. Onde se investigaria a viabilização da MIP pelas TICs.

A tendência observada no cenário atual indica o sistema BIM como a estrutura ideal e mais completa para desenvolvimento do projeto arquitetônico, uma vez que ele através dos recursos gráficos e da elaborada rede de gestão centralizada, consegue reunir equilibradamente as ferramentas das TICs e a gestão do projeto. Permitindo que o profissional tenha um aumento significativo em sua produtividade conseqüente de uma organização extrema e da integração dos diversos módulos e fases no momento da confecção e das alterações tão comuns no processo projetual.

Contudo, acredita-se que o importante não seria eleger qual ferramental das TICs seria a detentora de todas as soluções em todas as etapas do PPA, mas sim permitir ao projetista 
acesso e compartilhamento das informações geradas por várias plataformas de conhecimentos para projetos cada vez mais colaborativos e integrados. Permitindo aos usuários estar conscientes das etapas e atividades necessárias para o projeto e orientado para a tomada de decisões. A MIP continuaria orientando as escolhas dos projetistas nas etapas do PPA. Imaginando-se que cada projetista pudesse ser comparado a um único livro, cujo conteúdo estaria disponível para determinado projeto ou etapa dele, a integração facilitada desses usuários numa única plataforma ou possibilitando que houvesse uma comunicação continua, tais usuários agregados seriam extensões e ampliações de conteúdo, aproximando-se de uma grande biblioteca de inteligência "real" para uso direto nas soluções e resoluções de problemas de todos.

\section{REFERÊNCIAS BIBLIOGRÁFICAS}

ASBEA - ASSOCIAÇÃO BRASILEIRA DE ESCRITÓRIOS DE ARQUITETURA. Manual de Escopo de Projetos e Serviços para Coordenação de Projetos - Indústria Imobiliária. Imobiliária.

Manual de Escopo de Projetos e Serviços de Arquitetura e Urbanismo - Indústria

ABNT - ASSOCIAÇÃO BRASILEIRA DE NORMAS TÉCNICAS. Elaboração de Projetos de edificações - Arquitetura - NBR- 13532. Rio de Janeiro, 1995.

1993.

Discriminação de serviços para construção de edifícios - NBR- 12722. Rio de Janeiro,

Elaboração de caderno de encargos para execução de edificações - NBR- 12219. Rio de Janeiro, 1980.

. Diretrizes de serviços para construção de edifícios - NBR- 10006. Rio de Janeiro, 2001.

BERTEZINI, A. L. Métodos de avaliação do processo de projeto de arquitetura na construção de edifícios sob a ótica da gestão da qualidade. Tese de dissertação de Mestrado em Engenharia na Faculdade Escola Politécnica da USP. São Paulo, 2006.

BOUDON, P. Enseigmnement du projet et enseignement de la conception. In SAUVAGE, A. \& CHEIKROOUHOU, A. (Org). Conception d'Architecture - Projet à l'épreuve de l'enseignement. Paris: L'Harmattan, 2002, pp.29-39.

BOUTINET, J-P. Antropologia do projeto. 5a edição. Porto Alegre, Editora Artmed, 2002.

HAVE, S. T. Modelos de gestão: o que são e quando devem ser usados. São Paulo: Pearson Prentice Hall, 2003.

JURAN, J.M. A Qualidade desde o Projeto: os novos passos para o planejamento da qualidade em Produtos e serviços. São Paulo: Cengage Learning, 1992.

MAHFUZ, E.Ensaio sobre a razão compositiva. Belo Horizonte: Editora AP Cultural, 1995.

MARTINEZ, A. C. Ensaio sobre o projeto; tradução de Ane Lise Spaltemberg - Brasília: Editora de Brasília, 2000.

MELHADO, S. B. Qualidade do projeto na construção de edifícios: aplicação ao caso das empresas de incorporação e construção. São Paulo, 1994. 
Gestão, Cooperação e Integração para um Novo Modelo Voltado à Qualidade do Processo de Projeto na Construção de Edifícios. São Paulo, 2001.

PORTO CARREIRO, P.; RÊGO, R.M. "Mapas Mentais e Ferramentas Computacionais na Gestão da Informação do Processo de Ensino Projetual da Arquitetura, Urbanismo e Paisagismo", p. 590-594 . In: Proceedings of the XVII Conference of the Iberoamerican Society of Digital Graphics: Knowledge-based Design [=Blucher Design Proceedings, v.1, n.7]. São Paulo: Blucher, 2014.

PHILIPS, P. L. Briefing: A Gestão do projeto do design. São Paulo, Editora Blucher, 2008.

SCHÖN, D. Educando o Profissional Reflexivo. Porto Alegre, Ed. Artmed, 2000.

SILVA, S. M. Gestão do Processo Projetual Arquitetônico: conceitos, metodologias e ferramentas para viabilização das etapas projetuais. Trabalho de Graduação. Recife. UFPE, 2009.

VARGAS, R. V. Análise do Valor Agregado em Projetos. Rio de Janeiro: Editora Brasport, 2005. Gerenciamento de projetos. Rio de Janeiro: Editora Brasport, 2005. 